\title{
MECHANISTIC ASPECTS OF PHOTOCATALYTIC ACTIVITY OF METALLOPORPHYRIN-TITANIUM MIXTURES IN MICROEMULSIONS
}

\author{
Lorean Madriz ${ }^{\mathrm{a}, *}$ Hermes Carrero $^{\mathrm{a}}$, Oswaldo Núñez ${ }^{\mathrm{b}}$, Ronald Vargas ${ }^{\mathrm{a}}$ and Julio Herrera ${ }^{\mathrm{a}}$ \\ ${ }^{a}$ Chemistry Department, Simón Bolívar University, Caracas, Venezuela

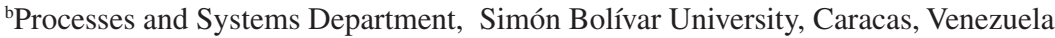

Recebido em 18/01/2016; aceito em 13/06/2016; publicado na web em 05/08/2016

\begin{abstract}
Photocatalytic activity of titanium citrate and its water-in-oil microemulsions mix with zinc (II) tetraphenylporphyrin have been studied by means of adding 4-chlorophenol and following its degradation using artificial ultraviolet and visible light. 4-Chlorophenol is degraded in 71 and $86 \%$, respectively, in $30 \mathrm{~min}$ with the generation of various intermediaries, whose possible formation mechanisms have been proposed based in the results of this research. The generation of benzene derivatives, different to those usually reported for this type of treatment, suggests the possibility of controlling the generation of intermediaries by simply changing the type of surfactant. In the case discussed here, we have derived a simple method for isomer generation of trimethylbenzene using a model organohalogenated compound as water contaminant and cetyltrimethylammonium bromide as surfactant.
\end{abstract}

Keywords: titanium (IV) citrate; porphyrin; microemulsion; photocatalysis; 4-chlorophenol.

\section{INTRODUCTION}

Corrinoid rings such as porphyrins and various titanium compounds as citrate and dioxide have been used as catalysts in many chemical reactions related to environmental mitigation due to their photochemical and electrochemical activation. ${ }^{1-3}$ The photochemical activity of titanium dioxide and its efficiency when combined with porphyrins, have been well studied, ${ }^{1,4-7}$ however, few reports have been devoted to investigate the photoactivity of titanium citrate mixtures. ${ }^{8}$

The role of citrate ion in biological processes has been well established. ${ }^{8,9}$ Citrate is a primary metabolite in Krebs cycle, and one of the abundant metallic ion binders in cellular fluids like human plasma. ${ }^{10,11}$ Furthermore, titanium is the second most abundant transition metal and is widely used in many items as manufacturing materials, medical implants, etc. ${ }^{12,13}$ Titanium (IV) citrate (abbreviated as Ti (IV) - cit) can serve as a soluble precursor to titanium oxide materials via the Pechini process ${ }^{14}$ and its structural effects have been studied on the human erythrocyte membrane, suggesting that disruption can be extended to other cells and affects its functions. ${ }^{15}$

Paradies et al. ${ }^{8}$ reported that Ti (IV) citrate, which is known as a strong oxidant agent, is readily reduced to Ti (III) citrate in aqueous solution under UV radiation. In the form of $\mathrm{Ti}$ (III) citrate, it has been used extensively to probe redox reactions involving enzyme catalytic functions. Tzou et al. ${ }^{16}$ found that the reduction of $\mathrm{Cr}$ (VI) by means of titanium citrate in aqueous solution undergoes a further increase due to the presence of Fe (III), thus proposing that the iron (III) citrate complex is excited by light and reduced to iron (II) citrate, which in turn reduces the $\mathrm{Cr}(\mathrm{VI})$. Furthermore, Madriz and co-workers ${ }^{7}$ demonstrated the efficient photocatalytic effect of the titanium citrate, individually and in combination with porphyrins. The efficiencies have been tested by degradation of 4-chlorophenol (4-CP) in microemulsions. Microemulsions have been widely used as micro- (or nano-) chemical reactors because of its special interfacial properties and the possibility for surfactants to influence the course of the reaction. ${ }^{14,16}$

Direct application process in photocatalytic reactors using artificial radiation involves operating costs that may hinder and/or decrease its implementation. ${ }^{17,18}$ Therefore, this methodology should

*e-mail: lmadriz@usb.ve be evaluated considering the use of solar radiation, ${ }^{17-22}$ so that its use is competitive, technologically and economically. This approach is particularly attractive for the recovery or degradation of sparingly soluble contaminants, especially in environments containing surfactants. ${ }^{19,23-26}$ The evaluation of photochemical and photocatalytic methodologies using solar simulation in laboratory scale is an appropriate strategy for reporting efficiencies of photo-induced processes that are capable of being applied on larger scales. ${ }^{18,20-22}$ Thus it allows to corroborate the effectiveness of procedures considered, and it gives an approximation of its performance under the action of sunlight in the ultraviolet and visible region of the spectrum.

In this research we studied the interaction of titanium citrate complexes on 4-CP conversion at more detailed level by means of identifying intermediaries as phenol, p-ethyltoluene and trimethylbenzene that allows the proposal of a reaction mechanism for the catalytic reaction of titanium citrate / zinc (II) tetraphenylporphyrin (ZnTPP) in water-in-oil (W/O) microemulsion.

\section{EXPERIMENTAL}

\section{Materials}

The surfactant cetyltrimethylammonium bromide (CTAB), $\mathrm{C}_{19} \mathrm{H}_{42} \mathrm{BrN}$, 99\% pure, 1-pentanol (99\%), 2-chlorophenol $\left(\mathrm{C}_{6} \mathrm{H}_{5} \mathrm{ClO}\right.$, $\geq 99 \%)$, 4-chlorophenol $\left(\mathrm{C}_{6} \mathrm{H}_{5} \mathrm{ClO}, \geq 99 \%\right)$, sodium acetate $(\geq 99 \%)$ and n-tetradecane $\left(\mathrm{C}_{14} \mathrm{H}_{30}, \geq 99 \%\right)$ were obtained from Sigma-Aldrich. Sulfuric acid and potassium hydrogen phthalate, $\left(\mathrm{C}_{8} \mathrm{H}_{5} \mathrm{O}_{4} \mathrm{~K}, \geq 99 \%\right)$ were obtained from Riedel de Haën and potassium dichromate (99\%) was obtained from Merck. Titanium dioxide, zinc (II) tetraphenylporphyrin and titanium citrate were synthesized in previous research. ${ }^{7}$ All other chemicals were reagent grade. The solutions were prepared in distilled and demineralized water after percolation through a demineralizer system of Milli-Q Reagent Water System, with a resistance higher than $15 \mathrm{M} \Omega / \mathrm{cm}$.

\section{Apparatus}

A Luzchem photo-reactor model LZC-5 with $8 \mathrm{~W}$ lamps (three on each side and four on the top) for ultraviolet radiation (UVB rays lamp 
centered at $300 \mathrm{~nm}$ with peak at $313 \mathrm{~nm}$ ) and visible radiation (fluorescent tubes cold white light) were used in photocatalytic studies of both systems (aqueous solution and microemulsion). The resulting samples from the photochemical treatment underwent analysis of chemical oxygen demand with a digestion reactor block (COD Reactor, $\mathrm{HACH}$ 16500-10) and also a liquid-liquid extraction using a mechanical stirrer Wrist Action Shaker brand Burrell model 75. The prepared samples were then analyzed with a gas chromatograph Hewlett Packard model 5890 series II Plus, attached to a Hewlett Packard 5973 mass selective detector. The chromatographic conditions were: initial oven temperature: $70^{\circ} \mathrm{C}(10 \mathrm{~min})$, with increases in temperature of $12^{\circ} \mathrm{C} / \mathrm{min}$ up to $170{ }^{\circ} \mathrm{C}$ and $15^{\circ} \mathrm{C} / \mathrm{min}$ up to $300^{\circ} \mathrm{C}$. Pressure: 10 psi. Injection flow: $60 \mathrm{~mL} / \mathrm{min}$. Injection mode: Splitless, and detection mode: Scan. A Solar Light Co. solar light simulator model LS 1000 with a $1000 \mathrm{~W}$ xenon lamp and the appropriate filters for producing visible (400-900), UV (290-400) or UV + visible (290-900) light were used in selected experiments. Solar light radiometer model PMA2100 and Ocean Optics fiber optic spectrometer model S1024dw were used to determine the radiation intensity and simulated spectra during each trial.

\section{Photocatalytic studies}

The photochemical studies were carried out in aqueous systems containing $13 \mathrm{mmol} \mathrm{L}^{-1}$ of $\mathrm{TiO}_{2}, 12 \mathrm{mmol} \mathrm{L}^{-1}$ of Ti-Cit, or a mixture of $12 \mathrm{mmol} \mathrm{L}^{-1}$ of $\mathrm{TiO}_{2}$ and $0.10 \mathrm{ZnTPP}^{\mathrm{mmol} \mathrm{L}} \mathrm{L}^{-1}$ (denoted by $\mathrm{TiO}_{2} /$ ZnTPP). The same study was developed in a W/O microemulsion (CTAB / pentanol / tetradecane / water), with a weight ratio of $0.10 / 1.63 / 4.58 / 0.21,{ }^{7}$ containing $12 \mathrm{mmol} \mathrm{L}^{-1}$ of Ti-Cit and $0.10 \mathrm{mmol}$ $\mathrm{L}^{-1} \mathrm{ZnTPP}$ (denoted by Ti - Cit/ZnTPP). Other types of mixtures were already studied in previous work. ${ }^{7}$ All samples contained $0.5 \mathrm{mmol}$ $\mathrm{L}^{-1}$ of 4-chlorophenol used as a model compound in order to follow its photoconversion.

It should be noted that the systems in which both $\mathrm{TiO}_{2}$ and porphyrin are present, the adsorption of the organic compound on the semiconductor surface occurs. This aspect was verified according to the adsorption test reported in the literature, ${ }^{27}$ and the estimated value in the conditions of the present work was $60 \%$.

The samples were placed in quartz cells or glass for the irradiation with UV $\left(\sim 30 \mathrm{~mW} / \mathrm{cm}^{2}\right)$ and visible light $\left(\sim 90 \mathrm{~mW} / \mathrm{cm}^{2}\right)$, respectively. Triplicates with 30 minutes irradiations were analyzed. All the resulting samples were treated to separate the components of interest. A liquid-liquid extraction was carried out by successive addition of: $0.50,1.0$, and $0.50 \mathrm{~mL}$ of $1.0 \mathrm{~mol} \mathrm{~L}^{-1}$ sodium acetate solution, each fraction being mechanically stirred for 10 minutes. The addition of the acetate solution allows the microemulsion phase separation of the polar and non-polar compounds. The aqueous fractions were treated again to separate the 4-CP by adding successive volumes of: 0.50 , 1.0 and $0.50 \mathrm{~mL}$ of dichloromethane and shaking each fraction for 10 minutes, in order to remove 4-CP and their photochemical degradation products. The aqueous solutions (without emulsion) were directly extracted with dichloromethane.

All samples were spiked with 2-chlorophenol (2-CP) before extraction, to obtain a concentration of $1.9 \mathrm{mmol} \mathrm{L}^{-1}$, in order to use it as internal standard in the chromatographic analysis. This analysis was conducted with a GC/MS under the same conditions referred previously in Apparatus section, to assess the reaction of 4-CP and to determine the products generated in its degradation. $2-\mathrm{CP}$ was used to correct possible errors arising from the extraction method. All products were detected by mass spectrometry. The mineralization of 4-CP during photocatalytic oxidation was assessed by measuring the chemical oxygen demand (COD). For measurements, $2.5 \mathrm{~mL}$ of sample were placed in a closed system and were treated with sulfuric acid and potassium dichromate for $2 \mathrm{~h}$ at $150{ }^{\circ} \mathrm{C}$, thus the total organic carbon was oxidized. Then, the absorbance of the resulting solution was measured at $600 \mathrm{~nm}$ wavelength. The COD was derived from a calibration curve prepared from solutions of potassium hydrogen phthalate.

\section{RESULTS AND DISCUSSION}

\section{Aqueous solution}

Table 1 shows the percentage of conversion of 4-CP in aqueous solution under the action of the titanium citrate in solution or titanium dioxide in suspension. In addition, we studied the influence of the ZnTPP adsorbed onto each one of the components mentioned above. The final suspensions were subsequently irradiated using UV and visible solar light, respectively.

Table 1. Conversion percentages of 4-chlorophenol in the different systems studied in aqueous solution

\begin{tabular}{cc}
\hline System & Conversion $(\%)$ \\
\hline $\mathrm{TiO}_{2} / \mathrm{UV}$ & 69 \\
$\mathrm{Ti}-\mathrm{Cit} / \mathrm{UV}$ & 65 \\
$\mathrm{TiO}_{2} / \mathrm{ZnTPP} / \mathrm{UV}$ & 34 \\
$\mathrm{TiO}_{2} / \mathrm{ZnTPP} / \mathrm{Vis}$ & 53 \\
$\mathrm{Ti}-\mathrm{Cit} / \mathrm{ZnTPP} / \mathrm{UV}$ & 58 \\
$\mathrm{Ti}-\mathrm{Cit} / \mathrm{ZnTPP} / \mathrm{Vis}$ & 23 \\
\hline
\end{tabular}

The spectra of the systems containing only Ti-Cit or $\mathrm{TiO}_{2}$ showed high absorbance in UV range. The photoactivation by UV absorption leads to the conversion of the organohalogenated compounds. Phenol, an intermediary of the reaction pathway, was detected in both systems.

A simple statistical analysis was performed on conversion values (triplicates) of 4-CP obtained with $\mathrm{TiO}_{2} / \mathrm{ZnTPP}$ mixture. These results indicate some difference between the irradiation with UV and visible light: 34 and 53\%, respectively; although $\mathrm{TiO}_{2} / \mathrm{ZnTPP}$ interactions should generate different sources of free radicals ${ }^{28}$ under different sources of light. The main interpretation concurs in sensitization of the photocatalysts by the ZnTPP chromosphere. ${ }^{28-32}$ No products were observed in the chromatograms obtained for these systems of study due to the fast intermediaries mineralization. In fact, quinoid compounds that would be generated according to the literature ${ }^{33}$ are strongly adsorbed on the catalyst yielding relatively high reaction rate. However, it is worth to point out that the presence of the expanded porphyrin radiation absorption range in the system, that promotes 4-CP degradation under visible radiation, did not occur in the absence of ZnTPP. In the systems in which Ti-Cit and porphyrin are used, a greater effect was observed: 58 and $23 \%$ of conversion of 4-CP under UV and visible, respectively. These observed results are probably due to the titanium citrate water solubility and its absorption in the UV region. In the systems under visible radiation phenol was found, however, in the systems under UV irradiation it was not detected.

The degradation of the organohalogen in aqueous phase, consisting of $\mathrm{TiO}_{2}$ or $\mathrm{TiO}_{2} / \mathrm{ZnTPP}$, was comparable with those reported in the literature for model organic compounds similar to the 4-CP. . $^{23,34,35}$ The interaction of light with titanium dioxide, porphyrin or a mixture of them, promotes the generation of activated oxygen, mainly hydroxyl radicals and singlet oxygen species. Those radicals attack organic matter causing its degradation. ${ }^{26,36}$ Accordingly, the detected product, phenol, can be considered as an intermediary of some stability in a consecutive reaction mechanism, which ends up in the total mineralization. Theurich and co-workers ${ }^{34}$ detected phenol in 
aqueous solutions during the photodegradation of the 4-CP with $\mathrm{TiO}_{2}$; the authors suggested that the organochloride is attacked by hydroxyl radicals to form various quinoid compounds, which then undergo the ring breakdown to produce aliphatic acids which are subsequently oxidized to $\mathrm{CO}_{2}$ and water. However, a direct reduction through the semiconductor conduction band is also possible yielding phenol as stable intermediary. This compound is then oxidized by the attack of hydroxyl radicals.

The results obtained for systems consisting of titanium citrate alone or mixed with porphyrin show significant 4-CP reactivity. It is known ${ }^{8}$ that titanium (IV) citrate irradiated with UV can be reduced to titanium (III) citrate whose reductive capacity allows the generation of free radicals. Special case is the mixture of Ti-Cit/ ZnTPP, which, to our knowledge, has not been thoroughly evaluated in chemical processes applications. Therefore, as a first approximation, the mechanism of reaction of 4-CP starts with a reductive step involving the $\mathrm{C}-\mathrm{Cl}$ bond cleavage. When titanium citrate is mixed with porphyrin the process may result in successive oxidations due to the generation of singlet oxygen.

The study carried out in aqueous solution allows establishing basis of comparison with catalytic studies carried out in non-conventional media such as a microemulsion.

\section{Microemulsions}

The results of the treatment in aqueous solution presented above, matched the results in oil-in-water $(\mathrm{O} / \mathrm{W})$ microemulsions obtained in our previous research, ${ }^{7}$ considering the uncertainties in the values obtained. This confirms the effectiveness of using O/W microemulsion for the treatment of poorly soluble organohalogen compounds without compromising the efficiency of the process. It is well known that the reaction rate in the presence of surfactants tends to decrease in comparison with the rate of the same reaction in aqueous solution. This is due to the presence of additional components in the system which tends to reduce the reaction rate, according to the mechanism of Langmuir-Hinshelwood, with concurrence of adsorption, that increases the time required to produce significant conversions. ${ }^{19,23,24,26}$ The studies carried out here differ from that assumption because the irradiation experiments were developed in 30 minutes in both the aqueous and the microemulsion systems. During this relatively short time selectivity toward the organohalogen might be manifested as it has been previously published. ${ }^{25}$

$\mathrm{W} / \mathrm{O}$ microemulsions were used as medium to study the mixture of Ti-Cit/ZnTPP. The prepared suspension was irradiated with UV and visible light to check the effect of the mixture on the degradation and to compare with the results obtained in previous studies. ${ }^{7}$ Titanium citrate absorbs in the UV region and its effect on degradation could be significant and even be reinforced when the compound is confined within the micelle that might act as a micro-reactor. The value obtained for the conversion of 4-CP in W/O microemulsion, $75 \%$, is higher than the value obtained in $\mathrm{O} / \mathrm{W}$ microemulsion, $52 \%$, and the last result comparable with the value obtained in aqueous solution, $58 \%$. These results are also statistically similar to those obtained when the system contained only Ti-Cit. The 4-CP degradation products detected were: 1,2,3-trimethylbenzene, phenol and p-ethyltoluene.

The radiation with visible light on a system containing porphyrin should significantly increase the photoconversion of 4-CP. This effect should be strengthened by the fact that the porphyrin is dissolved in the continuous oil phase. Indeed, the result ( $86 \%)$ is higher than for the study of $\mathrm{O} / \mathrm{W}$ microemulsion $(21 \%)$ and it is also higher than the one in aqueous solution (23\%). This means that the combination of the effect on the microemulsion micro-reactor with the Ti-Cit extension of the absorption range of the electromagnetic spectrum promoted by the porphyrin is very effective. The degradation products detected under the action of visible light are: phenol, 1,2,3-trimethylbenzene, 1,3,5-trimethylbenzene and p-ethyltoluene.

One possible explanation for the generation of the methylated compounds is that the titanium citrate complex, which is negatively charged, is attracted to the head of the surfactant by coulombic force due to its positive charge. The interaction between both compounds could destabilize the $\mathrm{C}-\mathrm{N}$ bonds of the methyl groups in the surfactant head. This interaction could be promoted by the hydrophobic effect of the four-methyl groups of the surfactant head, which displace some solvation water. ${ }^{37}$ The action of light in a composition like the one described before, could promote their transfer from the surfactant to the 4-CP intermediaries.

The delocalized charge on the cationic head and/or the irradiation itself ${ }^{37}$ can promote the electron transfer to generate the reduced form of the complex. ZnTPP at the interface may accept electrons from the complex or be activated directly by irradiation. The ZnTPP activation may occur similarly to the activation of a macrocycle cobalt complex caused by titanium citrate in aqueous solution as previously reported ${ }^{38}$ where the cobalt complex is reduced to its lowest oxidation state, +1 , from where the reaction starts. In the system with ZnTPP, the light promotes electrons to its excited state (LUMO) and the titanium complex exists as titanium (III) citrate; therefore, a redox reaction starts: oxidation to titanium (IV) citrate with the HOMO of the porphyrin and reduction of any organic compound with the electron in the LUMO of the porphyrin. In any case, the methylation of the benzene ring reported in this manuscript could occur in the interface, where the protons and the oxygenated radicals must have reduced transport capacity. The mixture of Ti-Cit and ZnTPP in microemulsions could be used to transform, via reduction, poorly soluble compounds using visible radiation.

The uncertainties degradation values reported for the catalytic systems studied in both aqueous solution and microemulsion (in this research and in previous one),${ }^{7}$ are on average about $\pm 10 \%$ despite having made comparisons with blank samples and used internal standard in the liquid-liquid extraction. Taking into account this uncertainty, the systems conducted in the presence of the mixture Ti-Cit and ZnTPP in W/O microemulsion and under visible and UV radiation show results similar to the value obtained for the system consisting of $\mathrm{TiO}_{2}$ in $\mathrm{O} / \mathrm{W}$ microemulsion under $\mathrm{UV}$ radiation, but significantly higher than the system in aqueous solution. Therefore, the micro-reactor effect of the microemulsion and the presence of porphyrin can overcome the inhibition predicted by the model of Langmuir-Hinshelwood regarding adsorption concurrency. ${ }^{19,23,24,26}$

Among the systems studied in this research, those that provided greater degradation percentages were the mixture Ti-Cit + ZnTPP in $\mathrm{W} / \mathrm{O}$ microemulsion and visible radiation, and the mixture of $\mathrm{TiO}_{2}$ in $\mathrm{O} / \mathrm{W}$ microemulsion under UV radiation, which have a degree of degradation similar and far superior to the systems in aqueous solution. It is important to highlight this fact because it constitutes evidence that the effect of micro-reactor assigned to the microemulsion is quite significant. The most relevant results are: $75 \%$ in $\mathrm{ZnTPP}$ and titanium citrate in W/O microemulsion system under UV radiation (products: 1,2,3-trimethylbenzene and p-ethyltoluene) and 86\% in ZnTPP and titanium citrate in W/O microemulsion system under visible radiation (products: 1,2,3-trimethylbenzene, 1,3,5-trimethylbenzene and p-ethyltoluene). These results are shown in Table 2, where are compared with results of previous studies. ${ }^{7}$

According to the parameter of toxicity LD-50 (fatal dose for half of a set of test organisms) of the intermediary compounds formed in the degradation of 4-CP, it is concluded that phenol is slightly more toxic than 4-chlorophenol, but both are more toxic than the 
Table 2. Conversion percentages of 4-chlorophenol in the most relevant systems studied in microemulsion compared with the results of previous research

\begin{tabular}{cc}
\hline System & Conversion $(\%)$ \\
\hline $\mathrm{Ti}-\mathrm{Cit} / \mathrm{ZnTPP} /(\mathrm{W} / \mathrm{O}) / \mathrm{UV}$ & 75 \\
$\mathrm{Ti}-\mathrm{Cit} / \mathrm{ZnTPP} /(\mathrm{W} / \mathrm{O}) / \mathrm{Vis}$ & 86 \\
$\mathrm{TiO}_{2} /(\mathrm{O} / \mathrm{W}) / \mathrm{UV}$ & $71^{*}$ \\
$\mathrm{ZnTPP} /(\mathrm{O} / \mathrm{W}) / \mathrm{UV}$ & $52^{*}$ \\
$\mathrm{ZnTPP} /(\mathrm{W} / \mathrm{O}) / \mathrm{Vis}$ & $62^{*}$ \\
$\mathrm{Ti}-\mathrm{Cit} / \mathrm{ZnTPP} /(\mathrm{O} / \mathrm{W}) / \mathrm{UV}$ & $52^{*}$ \\
\hline
\end{tabular}

* Results obtained in previous research. ${ }^{7}$

trimethyl isomers of benzene and 4-ethyltoluene. ${ }^{39}$ These compounds can be considered stable intermediaries of a consecutive reaction mechanism, which involves reducing routes followed by successive oxidation routes carried out through the action of the free radicals generated. ${ }^{33,40}$ Therefore, it can be considered that the toxicity of solutions of 4-chlorophenol decrease continuously during the catalytic processes developed.

In the cases of $\mathrm{TiO}_{2}$ and $\mathrm{ZnTPP}$, their oxidant mechanisms have been extensively studied, $4,27,28,30,32,36,41$ and are summarized as follows: the treatment of the titanium compound with the appropriate radiation generates electron-hole, i.e., an electron from the valence band is excited and passed to the conduction band leaving a deficiency of charge or hole. The electrons in the conduction band could attack the molecules of oxygen present inducing the formation of superoxide radicals. The hydrogen peroxide formed by that route would also be under the attack of electrons in the conduction band, and originate hydroxyl radicals. The radicals so formed, mainly $\mathrm{OH}^{\bullet}$, would be responsible for the oxidation of the organic compounds. Produced positive holes interact with $\mathrm{OH}^{-}$groups or $\mathrm{H}_{2} \mathrm{O}$ molecules of the aqueous medium to generate hydroxyl radicals, which may also attack organic matter. Finally, a recombination of electron and hole on the semiconductor is possible, which takes the system to its initial state. Now, if the same process of irradiation is applied to the sensitizer porphyrin, an electronic jump may occur which causes the displacement of electrons from HOMO to LUMO orbital generating an excited singlet state. Then, a cross intersystem induces the porphyrin going to an excited triplet state. In these excited state, the sensitizer can directly oxidize the organic compound or interact with triplet oxygen. If this latter step occurs, singlet oxygen can be formed that either oxidizes the organic compound and/or generates superoxide radicals. The sensitizer becomes a cationic radical and reacts with a halogenated organic compound giving rise to oxidation by-products. Otherwise, if there are $\mathrm{TiO}_{2}$ and porphyrin mixed in the system, the irradiation could cause the promotion of an electron from the orbital LUMO of porphyrin to the titanium oxide conduction band, generating the sensitizer radical cation. These species react with oxygen in the medium and produce superoxide radicals that eventually transforms to hydrogen peroxide and hydroxyl radicals, which in turn oxidize any organic compound present. Finally, the radical cation of porphyrin can be recombined with the previously loaned electron to restore the initial system. Additionally, the separate reactions for $\mathrm{TiO}_{2}$ and porphyrin described above might also occur.

Based on previous studies ${ }^{40}$ with iron citrate, which behaves in an equivalent manner to the titanium citrate, and the results of the present investigation, we propose a possible route for degradation of 4-chlorophenol in the presence of titanium citrate:

The following proposed mechanism is based on the unusual methylation products formed during the light irradiations conditions used in this work and previous results reported ${ }^{40}$ on photolysis of
$\mathrm{Fe}(\mathrm{III})$-citrate complexes in aerobic water. Figure 1 shows the simplification of titanium-citrate molecule used in the graphical representation. The key events on the mechanism are: the Ti(IV)-citrate complex capacity to be reduced and re-oxided by dissolved oxygen to form superoxide radical and the homolytic methyl transfers from the surfactant to the 4-chlorophenol into the micelle interface. Details are shown in Figure 2. As depicted, UV light or visible light, in the presence of a photo sensitizer, i.e., ZnTPP, promotes titanium reduction and $\mathrm{CO}_{2}$ evolution via homolytic Ti-O bond cleavage. Water molecule transfers a radical proton to the citrate molecule to yield the corresponding alcohol; meanwhile Titanium is reduced to $\mathrm{Ti}$ (III) and ${ }^{\circ} \mathrm{OH}$ substitutes $\mathrm{CO}_{2}$ as a ligand in the former complex. Dissolved oxygen oxidizes Ti back to Ti(IV) to yield superoxide radical $\left(\mathrm{O}_{2}{ }^{-}\right)$. This radical catalyzes the lost of chloride from 4-chlorophenol to yield the aromatic radical from which several reduction paths occur. For instance, in path $1,{ }^{34}$ phenol is produced via proton abstraction from water and/or from the surfactant $(\mathrm{RH})$. In path $\mathbf{2}$, the radical phenol $\mathrm{OH}$ is homolytically cleaved and a methyl group from the surfactant is transferred to yield p-methylphenol. Methylphenol undergoes further methylation from the surfactant to give trimethylbenzene and ethylmethylbenzene. In path $3, \mathrm{p}$ - and o- methyl transfers to methylphenol are shown. $\mathrm{O}_{2}^{--}$superoxide initiates 4-chlorophenol homolytic cleavage and initiation of steps 2 and 3 might occur from hydroxyl radical as shown in Figure 2.

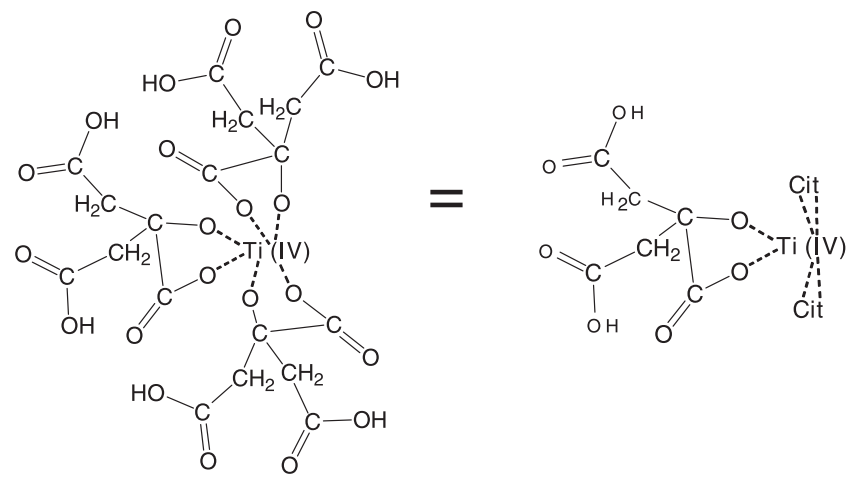

Figure 1. Simplification of titanium (IV) - citrate molecule used in the proposed mechanism

Based on the possible ways of reaction mentioned above (the reported for $\mathrm{TiO}_{2}$ and Figure 2), the products of 4-CP degradation seem to come from processes involving both reduction and oxidation. However, when the degradation is developed in the presence of $\mathrm{TiO}_{2}$, the oxidation is the predominant path (commonly reported in the literature), ${ }^{26,33,36}$ meanwhile, when it is done in the presence of titanium citrate, the predominant process is reduction, followed by successive oxidations. This can be corroborated by taking into account the results of the study of the chemical oxygen demand (COD). This parameter represents the amount of oxygen required to oxidize the organic matter contained in a sample; its decrease means a lower concentration of total organic carbon in the system. ${ }^{19-21,26}$ The analysis of COD is used to measure the amount of organic matter in waters and it is widely used in water treatment systems to evaluate the efficiency of mineralization processes, both in the laboratory and in industry. ${ }^{42}$ This analysis includes only systems with the higher percentages of degradation (Table 3): $\mathrm{TiO}_{2}$ in $\mathrm{O} / \mathrm{W}$ microemulsion and UV light $83 \%, \mathrm{TiO}_{2} / \mathrm{ZnTPP}$ in $\mathrm{O} / \mathrm{W}$ microemulsion and UV light $50 \%, \mathrm{TiO}_{2} / \mathrm{ZnTPP}$ in $\mathrm{O} / \mathrm{W}$ microemulsion and visible light $63 \%$, Ti-Cit in W/O microemulsion and UV light 20\%, Ti-Cit/ZnTPP in O/W microemulsion and UV light $18 \%$ and Ti-Cit/ ZnTPP in O/W microemulsion and visible light $20 \%$. These values were corrected 


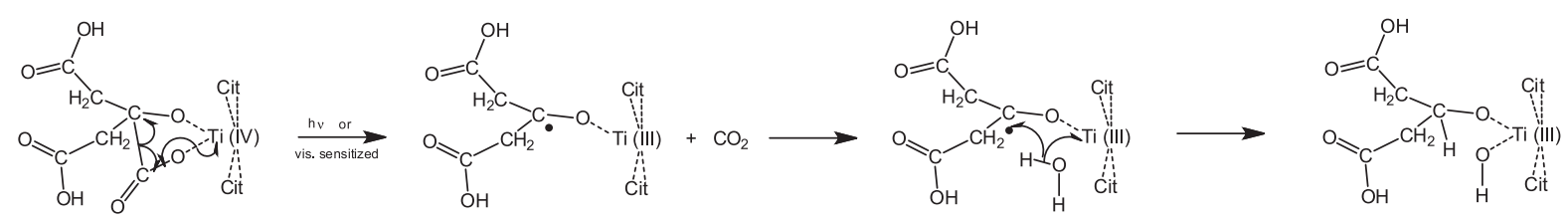

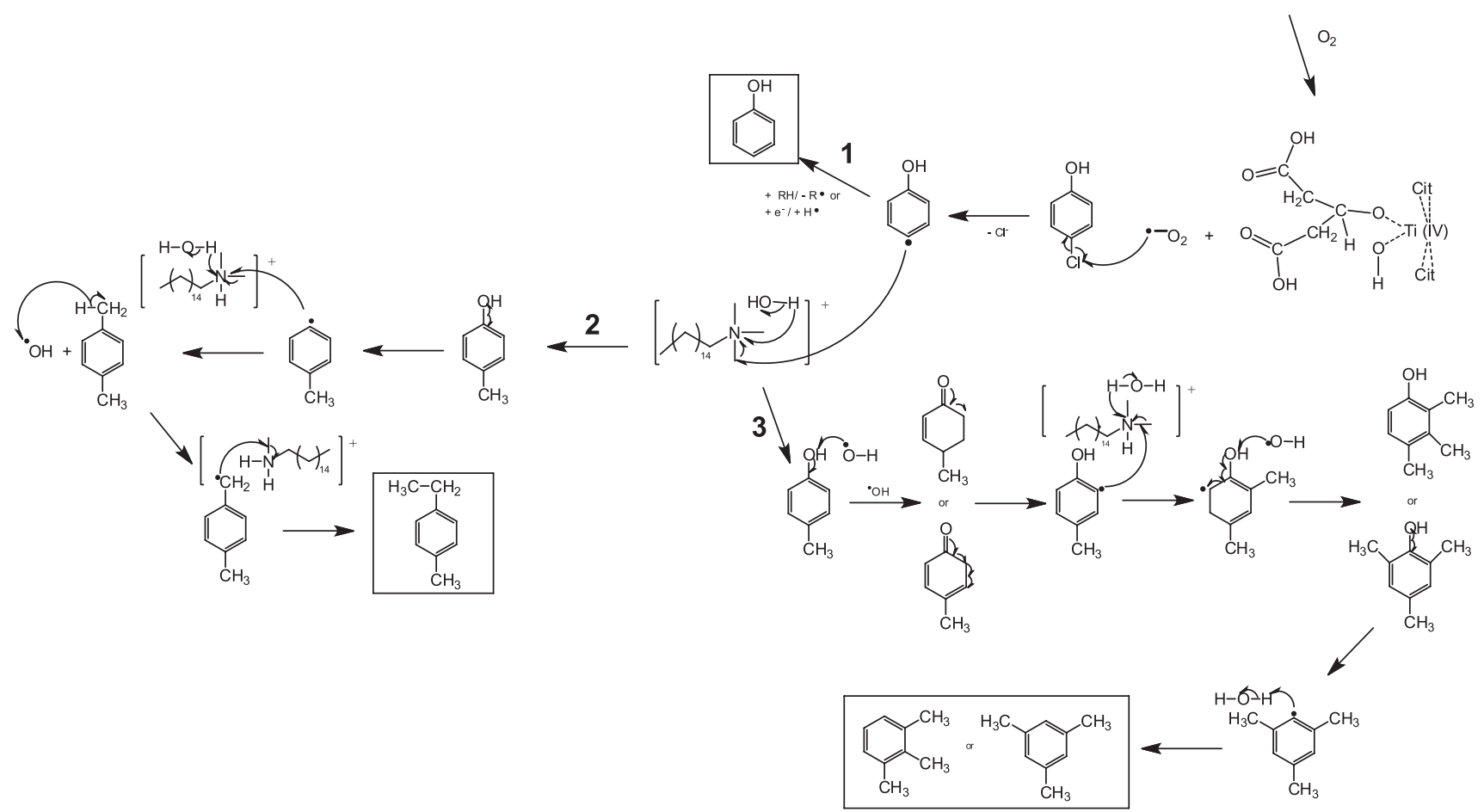

Figure 2. Proposed reaction mechanism that occurs in microemulsion systems, when titanium citrate is present

using the $\mathrm{COD}$ of the microemulsions without the main components of reaction. The surfactant that forms the microemulsion degrades very slowly in comparison with the organic compound. ${ }^{19,23-25}$ The COD values reveal that both 4-CP and its by-products follow the path up to the total oxidation.

Table 3. Decrease percentages in Chemical Oxygen Demand (COD) in selected systems for degradation of 4-chlorophenol in microemulsion

\begin{tabular}{cc}
\hline System & COD Decrease $(\%)$ \\
\hline $\mathrm{TiO}_{2} /(\mathrm{O} / \mathrm{W}) / \mathrm{UV}$ & 83 \\
$\mathrm{TiO}_{2} / \mathrm{ZnTPP} /(\mathrm{O} / \mathrm{W}) / \mathrm{UV}$ & 50 \\
$\mathrm{TiO}_{2} / \mathrm{ZnTPP} /(\mathrm{O} / \mathrm{W}) / \mathrm{Vis}$ & 63 \\
$\mathrm{Ti}-\mathrm{Cit} /(\mathrm{W} / \mathrm{O}) / \mathrm{UV}$ & 20 \\
$\mathrm{Ti}-\mathrm{Cit} / \mathrm{ZnTPP} /(\mathrm{O} / \mathrm{W}) / \mathrm{UV}$ & 18 \\
$\mathrm{Ti}-\mathrm{Cit} / \mathrm{ZnTPP} /(\mathrm{O} / \mathrm{W}) / / \mathrm{Vis}$ & 20 \\
\hline
\end{tabular}

According to the COD values shown, the most important mineralization is obtained when $\mathrm{TiO}_{2}$ is the catalyst which agrees with the maximum percentage of 4-CP degradation. For the other systems with titanium dioxide $\left(\mathrm{TiO}_{2} / \mathrm{ZnTPP}\right.$ in $\mathrm{O} / \mathrm{W}$ microemulsion for irradiation with $\mathrm{UV}$ and visible), the COD value decreases slightly in comparison to the 4-CP percentage of degradation; this may be due to the intermediates presence, for instance, phenol, that are not converted into $\mathrm{CO}_{2}$ and $\mathrm{H}_{2} \mathrm{O}$. This means that the slow step of the photodegradation reaction is different and faster than the mineralization one. The COD results prove that the systems containing $\mathrm{TiO}_{2}$ follow mainly an oxidation path, as reported in the literature,,$^{26,33,36}$ even though, a reduction path may also be present, according to the detected products. However, in systems containing Ti-Cit the path of the reaction is mainly reductive, but some oxidation is also present.

The scheme proposed in Figure 2 represents the possible reaction paths including both oxidation and reduction when microemulsions are used and citrate is present. It suggests one of the possible paths for the generation of intermediaries detected in the irradiated systems and previously reported. ${ }^{7}$ Phenol was detected in all used systems (this mechanism has been already reported) ${ }^{34}$ however, the trimethyl isomers of benzene and the p-ethyl toluene were detected only in systems consisting of Ti-Cit and Ti-Cit/ZnTPP. As shown in the proposed mechanism, the formation of these specific products was determined by the surfactant used in the system (CTAB). Changing the surfactant, other products might be formed since the alkyl transfer comes from it. We emphasize that, to our knowledge, this is the first time that these compounds are reported as intermediaries in a photochemical process.

The combination of three factors, the proximity of the organohalogenated compound to the redox reactions promoters (Ti-Cit, $\mathrm{TiO}_{2}$ and $\mathrm{ZnTPP}$ ) in a considerably small volume such as a micelle, the generation of free radicals and a source of high radiation power, originates high efficient photocatalytic reactions for degradation of 4-CP and it opens the possibility to modulate the reaction pathway as a function of the Ti species present in the reaction media. For instance, Ti-Cit may first induce $\mathrm{C}-\mathrm{Cl}$ bond cleavage in halogenated compounds conversion and then $\mathrm{TiO}_{2}$ may enhance oxidation by hydroxyl radical formation.

Finally, some systems were selected to assess the effect of solar light source in the degradation of $4-\mathrm{CP}$ in microemulsions. The 
Table 4. Conversion percentages of 4-chlorophenol in the selected systems studied in microemulsions under irradiation of solar simulator (SS) compared with systems studied under UV and visible light

\begin{tabular}{cccc}
\hline System & Conversion $(\%)$ & System & Conversion $(\%)$ \\
\hline $\mathrm{TiO}_{2} /(\mathrm{O} / \mathrm{W}) / \mathrm{SS}$ & 96 & $\mathrm{TiO}_{2} /(\mathrm{O} / \mathrm{W}) / \mathrm{UV}$ & 71 \\
$\mathrm{ZnTPP} /(\mathrm{O} / \mathrm{W}) / \mathrm{SS}$ & 94 & $\mathrm{ZnTPP} /(\mathrm{O} / \mathrm{W}) / \mathrm{UV}$ & 52 \\
$\mathrm{ZnTPP} /(\mathrm{W} / \mathrm{O}) / \mathrm{SS}$ & 99 & $\mathrm{ZnTPP} / \mathrm{W} / \mathrm{O}) / \mathrm{Vis}$ & 62 \\
$\mathrm{Ti}-\mathrm{Cit} / \mathrm{ZnTPP} /(\mathrm{O} / \mathrm{W}) / \mathrm{SS}$ & 97 & $\mathrm{Ti}-\mathrm{Cit} / \mathrm{ZnTPP} /(\mathrm{O} / \mathrm{W}) / \mathrm{UV}$ & 52 \\
$\mathrm{Ti}-\mathrm{Cit} / \mathrm{ZnTPP} /(\mathrm{W} / \mathrm{O}) / \mathrm{SS}$ & 86 & $\mathrm{Ti}-\mathrm{Cit} / \mathrm{ZnTPP} / \mathrm{W} / \mathrm{O}) / \mathrm{UV}$ & 75 \\
& & $\mathrm{Ti}-\mathrm{Cit} / \mathrm{ZnTPP} / \mathrm{W} / \mathrm{O}) / \mathrm{Vis}$ & 86 \\
\hline
\end{tabular}

systems were irradiated in a solar simulator and the results were compared to the UV and visible light (Table 4).

According to the results of Table 4, all systems under the effect of the solar simulator showed a higher decrease in the concentration of 4-CP than the systems irradiated with UV and visible light separately. Phenol was the only product detected. Therefore, it is confirmed that the use of solar light is economically more convenient than artificial sources, allowing to assess the potential applicability to industrial scale. ${ }^{36}$

\section{CONCLUSIONS}

Chloro benzene conversion presented in this work represents pioneering evidence of the photoactivity of the titanium citrate in a medium such as a W/O microemulsion. Phenol was the main intermediary in the majority of the treated systems. However, in systems where Ti-Cit was present, alone or mixed with ZnTPP, trimethylbenzene isomers and p-ethyltoluene were also formed in a significant amount. These intermediaries were originated through a mechanism of consecutive character. The COD values suggest that the subsequent reactions followed an oxidation path.

The generation of benzene derivatives, different to those usually reported for this type of treatment, suggests the possibility of controlling the generation of intermediaries by simply changing the type of surfactant. In the case discussed here, we have derived a simple method for isomer generation of trimethylbenzene using an organohalogen as starting material and cetyltrimethylammonium bromide as a surfactant.

The photoactivity of titanium citrate is revealed in both aqueous solution and microemulsion. For the first time, evidence is shown for the photocatalytic effect of the titanium citrate in a medium such as a microemulsion and it opens the possibility to modulate the reaction pathway, promoted by both $\mathrm{TiO}_{2}$ and titanium (IV) citrate.

\section{REFERENCES}

1. Diebold, U.; Surf. Sci. Rep. 2003, 48, 53.

2. Shiragami, T.; Matsumoto, J.; Inoue, H.; Yasuda; M.; J. Photochem. Photobiol., C 2005, 6, 227.

3. Lee, M. S.; Park, S. S.; Lee, G. - D.; Ju., Ch.-S.; Hong, S.-S.; Catal. Today. 2005, 101, 283.

4. Gaya, U. I.; Abdullah, A. H.; J. Photochem. Photobiol., C 2008, 9, 1.

5. Shan, M. N.; Wang, S. S.; Bian, Z. Q.; Liu, J. P.; Zhao, Y. L.; Sol. Energy Mater. Sol. Cells 2009, 93, 1613.

6. Chatterjee, D.; Dasgupta, S.; J. Photochem. Photobiol., C 2005, 6, 186.

7. Madriz, L.; Carrero, H.; Herrera, J.; Cabrera, A.; Canudas, N.; Fernández, L.; Top. Catal. 2011, 54, 236.

8. Paradies, J.; Crudass, J.; Mackay, F.; Yellowlees, L.; Montgomery, J.; Parsons, S.; Oswald, I.; Robertson, N.; Sadler, P.; J. Inorg. Biochem. 2006, 100, 1260.
9. Gámez, V. M.; Sierra-Alvarez, R.; Waltz, R. J.; Field. J. A.; Biodegradation 2009, 20, 499.

10. Lippard, S. J.; Berg, J. M.; Principles of Bioinorganic Chemistry, Chapter 12, University Science Books: Mill Valley, 1994.

11. Fraústo da Silva, J. J. R.; Williams, R. J. P.; The Biological Chemistry of the Elements: the Inorganic Chemistry of Life, Oxford University Press: Oxford, 2001.

12. Panagiotidis, P.; Kefalas, E. T.; Raptopoulou, C. P.; Terzis, A.; Mavromoustakos, Th.; Salifoglou, A.; Inorg. Chim. Acta 2008, 361, 2210.

13. Yuan, Y.; Li, X.; Sun, J.; Ding, K.; J. Am. Chem. Soc. 2002, 124, 14866.

14. Pechini, M. P.; US Pat. 3231328, 1966.

15. Suwalsky, M.; Villena, F.; Norris, B.; Soto, M. A; Sotomayor, C. P.; Messori, L.; Zatta, P.; J. Inorg. Biochem. 2005, 99, 764.

16. Tzou, Y. M.; Wang, S. L.; Wang, M. K.; Colloids Surf., A 2005, 253, 15.

17. Muñoz, I.; Rieradevall, J.; Torrades, F.; Peral, J.; Domènech, J.; Sol. Energy 2005, 79, 369

18. Malato, S.; Blanco, J.; Alarcón, D. C.; Maldonado, M. I.; Fernández-Ibáñez, P.; Gernjak, W.; Catal. Today. 2007, 122, 137.

19. Pardo, G.; Vargas, R.; Núñez, O.; J. Phys. Org. Chem. 2008, 21, 1072.

20. Vargas, R.; Núñez, O.; Sol. Energy 2010, 84, 345.

21. Malato, S.; Blanco, J.; Alfonso, V.; Alarcón, D. C.; Maldonado, M. I.; Cáceres, J.; Gernjak, W.; Sol. Energy 2003, 75, 329.

22. Malato, S.; Blanco, J.; Alfonso, V.; Richter, C.; Appl. Catal., B 2002, 37, 1.

23. Liu, J. W.; Han, R.; Wanga, H. T.; Zhao, Y.; Chu, Z.; Wu, H. Y.; Appl. Catal., B 2011, 103, 470

24. Horikoshi, S.; Minami, D.; Ito, S.; Sakai, H.; Kitamoto, D.; Abe, M.; Serpone, N.; J. Photochem. Photobiol., A 2011, 217, 141.

25. Barrios, N.; Sivov, P.; D`Andrea, D.; Núñez, O.; Int. J. Chem. Kinet. 2005, 37, 414

26. Vargas, R.; Núñez, O.; J. Mol. Catal. A: Chem. 2008, 294, 74.

27. Vargas, E.; Vargas, R.; Núñez, O.; Appl. Catal., B 2014, 156-157, 8.

28. Mele, G.; Del Sole, R.; Vasapollo, G.; García-López, E.; Palmisano, L.; Schiavello, M.; J. Catal. 2003, 217, 334.

29. Grätzel, M.; J. Photochem. Photobiol., C 2003, 4, 145.

30. Nazeeruddin, Md. K.; Baranoff, E.; Grätzel, M.; Sol. Energy 2011, 85, 1172 .

31. Malinka, E. A.; Kamalov, G. L.; Vodzinskii, S.V.; Melnik, V. I.; Zhilina, Z. I.; J. Photochem. Photobiol. A 1995, 90, 153.

32. Zangeneh, H.; Zinatizadeh, A. A. L.; Habibi, M.; Akia, M.; Hasnain Isa, M.; J. Ind. Eng. Chem. 2015, $26,1$.

33. Bahnemann, D.; Sol. Energy 2004, 77, 445.

34. Theurich, J.; Lindner, M.; Bahnemann. D. W.; Langmuir 1996, 12, 6368.

35. Shi, Z.; Sigman, M. E.; Ghosh, M. M.; Dabestani, R.; Environ. Sci. Technol. 1997, 31, 3581.

36. Hoffmann, M. R.; Martin, S. T.; Choi, W.; Bahnemann, D. W.; Chem. Rev. 1995, 95, 69 .

37. Bunton, C.; Adv. Colloid Interface Sci. 2006, 123-126, 333.

38. Szajna-Fuller, E.; Bakac, A.; Eur. J. Inorg. Chem. 2010, 17, 2488. 
39. The Physical and Theoretical Chemistry Laboratory, Oxford University, England Chemical Safety Information. Safety data for 1,2,3-trimethylbenzene. In: http://msds.chem.ox.ac.uk (2011)

40. Chen, Y.; Wu, F.; Zhang, X.; Deng, N.; Bazhin, N.; Glebov, E.; J. Coord. Chem. 2007, 60, 2431.
41. López, D.; Lozada, W.; Blanco, S.; Durán, G.; Madriz, L.; Vargas, R.; Avances en Ciencias e Ingeniería 2011, 2, 47.

42. Panizza M. In Importance of electrode material in the electrochemical treatment of wastewater containing organic pollutants. Electrochemistry for the Environment; Comninellis, Ch., Chen G., eds.; Springer Science Business Media: New York, 2010, pp. 25-54. 